\title{
USO DO EYE TRACKING PARA MEDIÇÃO DA SATISFAÇÃO PARA TESTES DE USABILIDADE EM INTERFACES WEB
}

\section{USE OF EYE TRACKING FOR MEASURING SATISFACTION ON WEB INTERFACE USABILITY TESTS}

Aline Girardi Gobbi ${ }^{1}$, M.Sc.

Tiago Catecati ${ }^{2}$, M.Sc.

Eugenio Andrés Díaz Merino ${ }^{3}$, D.Sc.

Giselle Schmidt Andrés Díaz Merino ${ }^{4}$, D.Sc.

Marcelo Gitirana Gomes Ferreira ${ }^{5}$, D.Sc.

(1) Universidade Federal de Santa Catarina e-mail:aline.gobbi@gmail.com

(2) Universidade Federal de Santa Catarina e-mail:tcatecati@gmail.com

(3) Universidade Federal de Santa Catarina e-mail:eugenio.merino@ufsc.br

(4) Universidade Federal de Santa Catarina e-mail: gisellemerino@gmail.com

(5)Universidade do Estado de Santa Catarina e-mail:marcelo.gitirana@gmail.com 


\section{$16^{\circ}$ \\ ERGODESIGN USIHC CINAHPA}

$16^{\circ}$ Ergodesign - Congresso Internacional de Ergonomia e Usabilidade de Interfaces Humano Tecnológica: Produto, Informações Ambientes Construídos e Transporte

$16^{\circ}$ USIHC - Congresso Internacional de Ergonomia e Usabilidade de Interfaces Humano Computador

CINAHPA | 2017 - Congresso Internacional de Ambientes Hipermídia para Aprendizagem.

\section{Palavras-chave: Usabilidade, Eye Tracking, Satisfação}

Esta pesquisa trata da medida de satisfação de usuários no uso de interfaces web. Procurou-se relacionar resultados obtidos com medições de movimento oculares, utilizando um dispositivo de eye tracking, com os questionários SUS e PrEmo, utilizados para medição da satisfação. Como resultado, observou-se que existe relação entre o número de fixações do olhar e suas dispersões com a satisfação do usuário.

\section{Key-words: Usability, Eye Tracking, Satisfaction}

This research is about the measure of user satisfaction in the use of web interfaces. We correlate results obtained with ocular movement measurements using an eye tracking device with the SUS and PrEmo questionnaires, used to measure satisfaction. As a result, we observed that there is a relationship between the number of fixations of the eye and its dispersions with the satisfaction of the user.

\section{Introdução}

Durante o desenvolvimento de um teste de usabilidade, é possível que informações relacionadas à satisfação do usuário não sejam percebidas. De acordo com Kretschmar et al. (2013), as medições relativas à satisfação são limitadas a um comportamento observável evidente. Através da utilização de entrevistas, questionários ou protocolos think aloud, os pesquisadores devem confiar na memória de um participante e julgamentos subjetivos como um meio de obter insights sobre os processos cognitivos internos e estados emocionais. Um achado comum dentro de neurociência cognitiva é que a percepção subjetiva da pessoa do seu próprio comportamento nem sempre corresponde com a sua atividade neural subjacente (KRETSCHMAR et al., 2013). De forma simplificada, o autor coloca que as pessoas nem sempre sabem o que está acontecendo dentro de suas próprias cabeças.

As tecnologias de medição de sinais psicofisiológicos podem auxiliar na identificação de variações emocionais, gerando dados quantitativos que venham a reforçar informações subjetivas relativas à satisfação, usualmente coletadas com métodos como questionários e entrevistas, como o SUS (System Usability Scale, BROOKE, 2013) e o PrEmo (Measure Product Emotion, CAICEDO, G.D \& DESMET, 2009).

A pergunta que surge diante da situação exposta é: como os sinais oculares provenientes de medições com eye tracking (rastreamento ocular), mais especificamente as fixações do olhar e as dispersões do olhar (momentos em que o o foco dos usuários sai das zonas de interesse), podem ser utilizados em testes de usabilidade para identificar a satisfação do usuário durante a interação com uma interface?

O objetivo desta pesquisa é verificar a possibilidade de medição da satisfação do usuário em testes de usabilidade por meio das fixações e das dispersões do olhar, medidas obtidas com o eye tracking. Para tal, pretende-se realizar um procedimento experimental utilizando o eye tracking, comparando os dados gerados por esta ferramenta com outros dados gerados por ferramentas de análise subjetiva (ferramenta SUS e PrEmo).

\section{REFERENCIAL TEÓRICO}

Para um melhor entendimento do tema abordado, foi apresentada a definição dos principais termos relativos ao tema tratados nesta pesquisa, alinhadas com a visão dos pesquisadores.

\subsection{Usabilidade}

A definição de usabilidade adotada nesta pesquisa é a da Norma ISO 9241/11 (1998), que define usabilidade como a medida em que um sistema, produto ou serviço pode ser usado por usuários específicos para se atingir objetivos específicos com eficácia, eficiência e satisfação em um determinado contexto de uso. Por meio desta 


\section{$16^{\circ}$ \\ ERGODESIGN USIHC CINAHPA}

definição, entende-se que a satisfação é uma das medidas da usabilidade, que será focada neste trabalho.

\subsection{Satisfação}

Também de acordo com a ISO 9241:11 (1998), a Satisfação mede o quanto os usuários estão livres de desconforto, gostam de utilizar o produto ou aceitam a carga mental imposta pela tarefa. A satisfação pode estar relacionada aos objetivos da usabilidade (eficiência e facilidade de aprendizagem).

A satisfação se mostra mais complexa de ser medida, em comparação com a eficácia e a eficiência, por tratar-se de uma medida subjetiva, que depende da percepção dos usuários. Existem alguns métodos de medição de satisfação em formato de questionário, como o SUS (System Usability Scale), desenvolvido por Brooke (2013), que permite uma aplicação ampla para avaliação de diversos tipos de produtos e sistemas. Algumas vantagens da aplicação do SUS incluem a facilidade de aplicação e a possibilidade de uso em amostras pequenas com resultados válidos.

Outros métodos, como o PrEmo (Measure Product Emotion, desenvolvido por Desmet (2002), é também utilizado para medir o sentimento despertado por um produto no usuário. A ferramenta foi atualizada por Caicedo (2009) e consiste em um conjunto de figuras que $o$ participante pode escolher, representando 14 emoções diferentes (ARAÚJO et al., 2015).

Essas ferramentas podem ser bastante úteis para a medição da satisfação, porém possuem a desvantagem de não gerarem dados quantitativos, o que pode provocar erros de interpretação.

\subsection{Eye Tracking (Rastreamento Ocular)}

Eye-tracking é um método que, por meio de um óculos dotado de uma tecnologia específica envolvendo o uso de micro câmeras (Figura 1), permite a captura dos movimentos oculares. As principais medidas que o eye tracking pode fornecer são: $16^{\circ}$ Ergodesign - Congresso Internacional de Ergonomia e Usabilidade de Interfaces Humano Tecnológica: Produto, Informações Ambientes Construídos e Transporte

$16^{\circ}$ USIHC - Congresso Internacional de Ergonomia e Usabilidade de Interfaces Humano Computador

CINAHPA | 2017 - Congresso Internacional de Ambientes Hipermídia para Aprendizagem.

Fixação do olhar: A fixação é um momento em que os olhos estão relativamente imóveis (Poole \& Ball, 2005). De acordo com Granka et al. (2008) “a fixação é geralmente definida como um olhar espacialmente estável com duração de aproximadamente 200-300 milissegundos, durante o qual a atenção visual é dirigida à uma área específica da exibição visual". No contexto web, as fixações referem-se a informações sobre os elementos da interface que captam a atenção do usuário e por quanto tempo o elemento captou sua atenção. Por meio da análise do local das fixações, também é possível verificar a ordem em que o usuário visualizou cada elemento da interface. Com relação às fixações do olhar, três medidas podem ser obtidas: 1) Número de fixações, que se refere à quantidade de fixações que são contadas em um determinado período de tempo, ou em uma região específica da tela (interface) ou de um objeto; 2) Tempo de fixação, que consiste no tempo que o participante passou fixando em um mesmo ponto. Segundo alguns autores, quando o tempo de fixação é muito alto, pode significar um aumento da carga cognitiva no usuário (IQBAL et al., 2005; SCHULTHEIS \& JAMESON, 2004) e;

3) Dispersão das fixações, que refere-se à quantidade de fixações afastadas das áreas de interesse.

Sacadas: As sacadas ou movimento sacádico, é baseado nas fixações de um ponto a outro e estabelece o padrão de fixação do olhar, refletindo como um usuário interpreta um estímulo visual (BERGSTRAM \& SCHALL, 2014).

Piscadas: O dispositivo eye tracking retorna o número e a duração das piscadas dos participantes durante a execução da tarefa. Tsai et al. (2007) descobriram que a frequência e duração das piscadas corresponde à performance da tarefa, $\mathrm{e}$ concluíram que mudanças nas métricas relativas às piscadas eram devidas à carga mental e fadiga do operador, induzidas pela tarefa.
Realização:

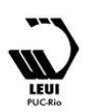




\section{$16^{\circ}$ \\ ERGODESIGN USIHC CINAHPA}

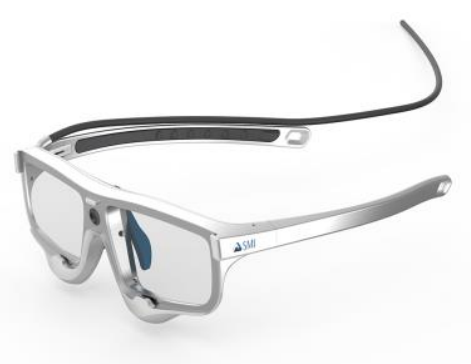

Figura 1: Dispositivo Eye Tracking SMI

Fonte: Site da SMI Senso Motoric Instruments (2016).

\section{PROCEDIMENTOS METODOLÓGICOS}

Conforme o objetivo desta pesquisa, foi realizado um experimento com 5 participantes. Os participantes permaneceram sentados na frente de um computador, utilizando o óculos eye tracker enquanto executaram duas tarefas em um web site (objeto de pesquisa). Após a execução das tarefas, o usuário respondeu ao questionário SUS e o PrEmo. Os pesquisadores permaneceram sentados ao lado dos participantes durante todo o tempo da pesquisa, esclarecendo eventuais dúvidas dos participantes.

Ao final do experimento, os dados obtidos com o eye tracking (número de fixações e local das fixações (dispersões) foram comparados com os resultados obtidos com os testes SUS e PrEmo a fim de avaliar se existe relação dos movimentos oculares com a satisfação do usuário no uso de uma interface web.

\subsection{Objeto de pesquisa e Tarefas}

O objeto desta pesquisa foi o site da prefeitura municipal de Florianópolis, na seção de saúde (http://www.pmf.sc.gov.br/saude). Nesta página, foi pedido que o usuário execute as seguintes tarefas:

1) Dado que o atendimento pelo SUS é feito por áreas, cada bairro ou parte de um bairro é atendido em um determinado posto de saúde. O usuário deve procurar, na página dada, informações sobre onde ele pode ser atendido e clicar no link onde ele acredita que encontrará a informação; $16^{\circ}$ Ergodesign - Congresso Internacional de Ergonomia e Usabilidade de Interfaces Humano Tecnológica: Produto, Informações Ambientes Construídos e Transporte

$16^{\circ}$ USIHC - Congresso Internacional de Ergonomia e Usabilidade de Interfaces Humano Computador

CINAHPA | 2017 - Congresso Internacional de Ambientes Hipermídia para Aprendizagem.

2) Finalizada a tarefa 1 , na próxima página, o usuário deve encontrar o endereço do posto de saúde em que ele será atendido (nome da rua e número).

Para a tarefa 1, existem 3 opções de rota para sua realização que são as áreas destacadas em vermelho, também chamadas de áreas de interesse (AOI, Areas of Interest, em inglês), conforme a Figura 2.

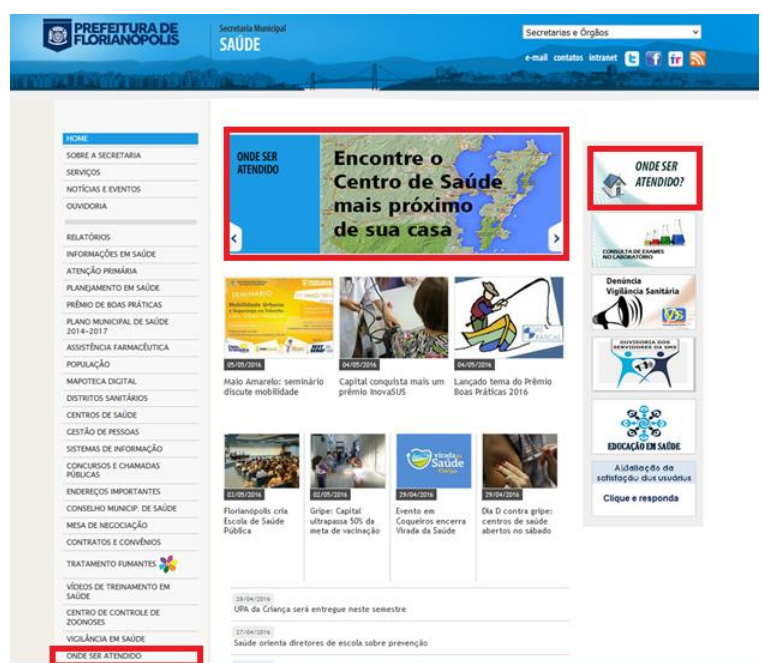

Figura 2: Áreas clicáveis necessárias para completar a tarefa 1 (AOI).

Fonte: Site da Prefeitura de Florianópolis

As três opções levam para a mesma página, onde foi pedido que se execute a Tarefa 2 (Figura 3 ).

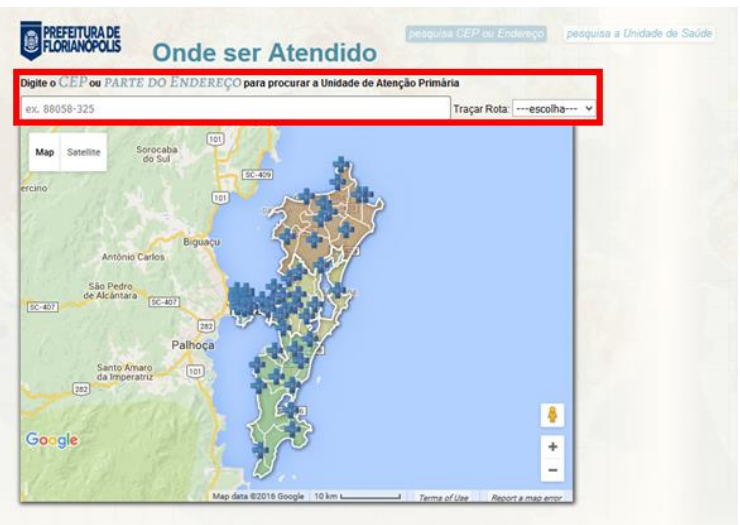

Figura 3: Página da Tarefa 2 com a AOI destacada. Fonte: Site da Prefeitura de Florianópolis

Digitando o CEP ou o endereço na barra de busca 


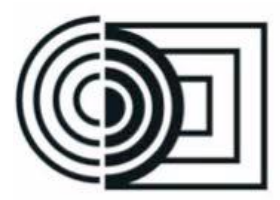

da página, pode ser feita a busca pela unidade de saúde mais próxima, completando, dessa forma, a Tarefa 2 (Figura 4).

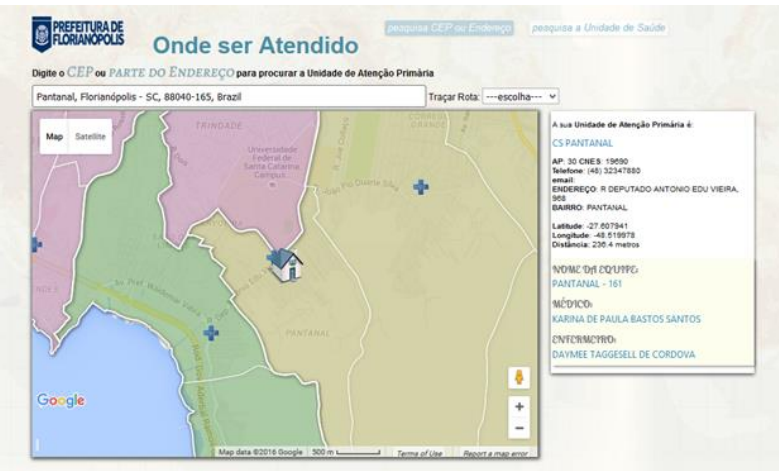

Figura 4: Exemplo de resultado de busca por CEP, resultado da Tarefa 2.

Fonte: Site da Prefeitura de Florianópolis

\section{RESULTADOS}

Os testes foram aplicados conforme descrito na seção de procedimentos metodológicos desta pesquisa. Os dados obtidos com o eye tracking ficam disponíveis em formato de vídeo, sendo que alguns dados podem ser salvos em formato de imagem para a realização de análises e demonstrações. As Figuras 5 à 14 mostram os resultados dos caminhos percorridos pelo olhar para cada participante, onde é possível verificar as dispersões do olhar, bem como os locais de fixação do olhar nas áreas da tela.

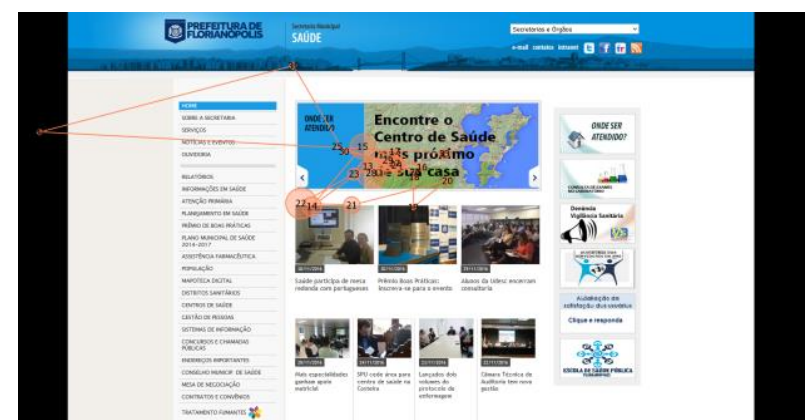

Figura 5: Mapa de Fixações (Gazeplot) da Tarefa 1 para o Participante 1 (P1).

Fonte: Print Screen do programa de análise dos dados do eye tracking (BeeGaze). $16^{\circ}$ Ergodesign - Congresso Internacional de Ergonomia e Usabilidade de Interfaces Humano Tecnológica: Produto, Informações Ambientes Construídos e Transporte

$16^{\circ}$ USIHC - Congresso Internacional de Ergonomia e Usabilidade de Interfaces Humano Computador

CINAHPA | 2017 - Congresso Internacional de Ambientes Hipermídia para Aprendizagem.

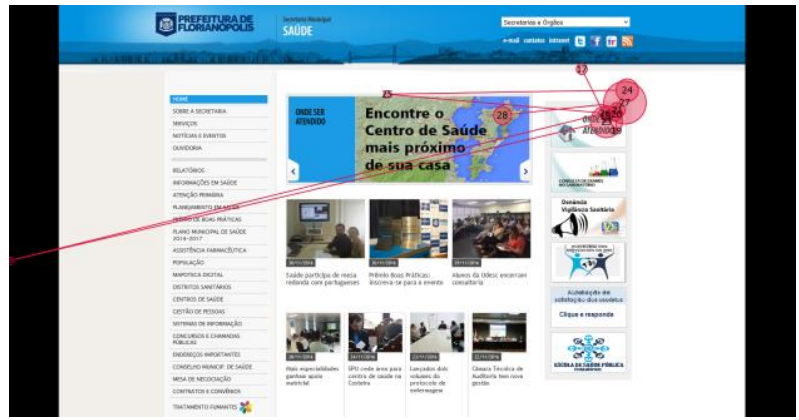

Figura 6: Mapa de Fixações (Gazeplot) da Tarefa 1 para o Participante 2 (P2).

Fonte: Print Screen do programa de análise dos dados do eye tracking (BeeGaze).

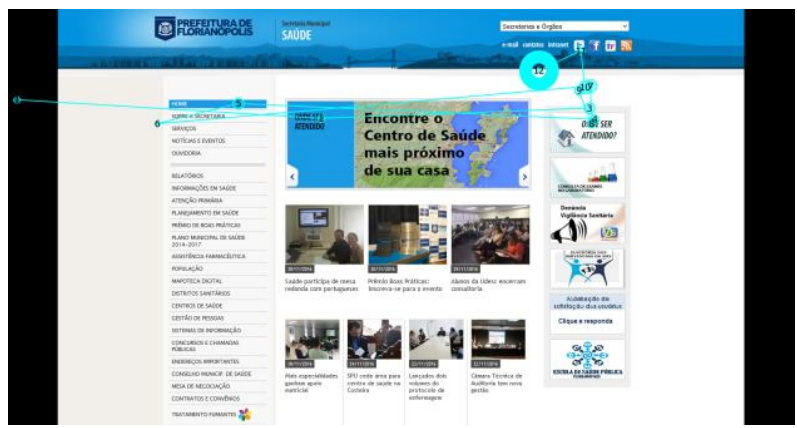

Figura 7: Mapa de Fixações (Gazeplot) da Tarefa 1 para o Participante 3 (P3).

Fonte: Print Screen do programa de análise dos dados do eye tracking (BeeGaze).

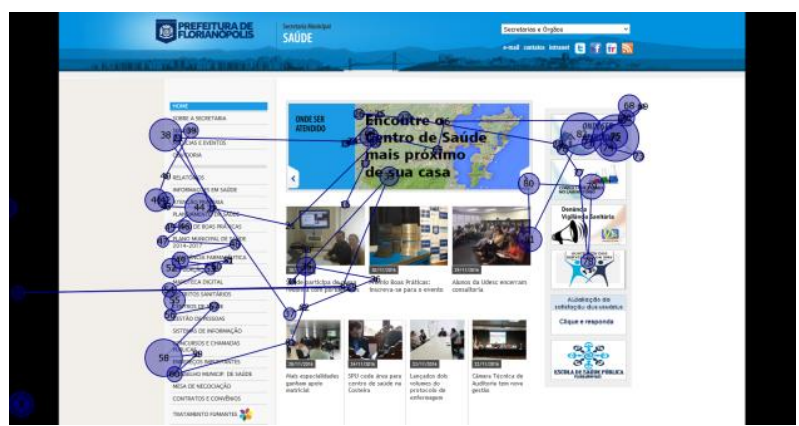

Figura 8: Mapa de Fixações (Gazeplot) da Tarefa 1 para o Participante 4 (P4).

Fonte: Print Screen do programa de análise dos dados do eye tracking (BeeGaze).
Realização:
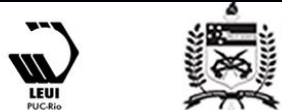


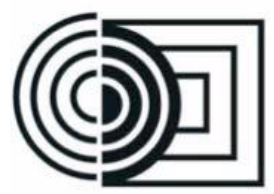

ERGODESIGN USIHC CINAHPA $16^{\circ}$ Ergodesign - Congresso Internacional de Ergonomia e Usabilidade de Interfaces Humano Tecnológica: Produto, Informações Ambientes Construídos e Transporte

$16^{\circ}$ USIHC - Congresso Internacional de Ergonomia e Usabilidade de Interfaces Humano Computador

CINAHPA | 2017 - Congresso Internacional de Ambientes Hipermídia para Aprendizagem.

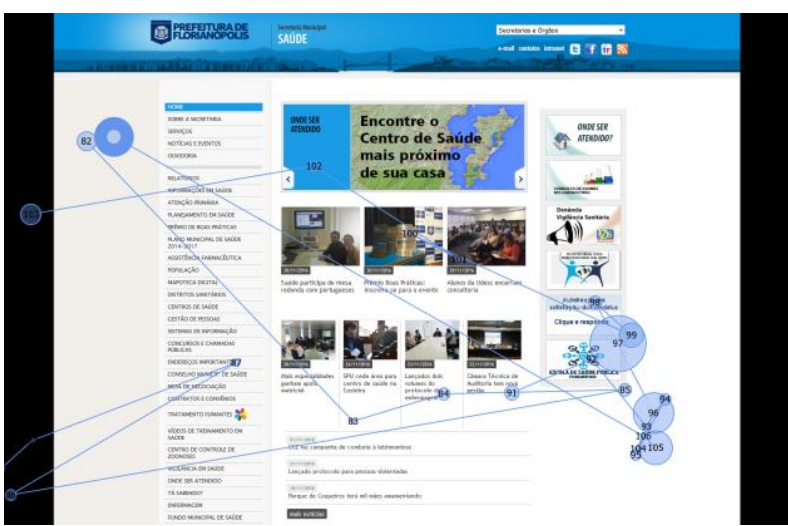

Figura 9: Mapa de Fixações (Gazeplot) da Tarefa 1 para o Participante 5 (P5).

Fonte: Print Screen do programa de análise dos dados do eye tracking (BeeGaze).

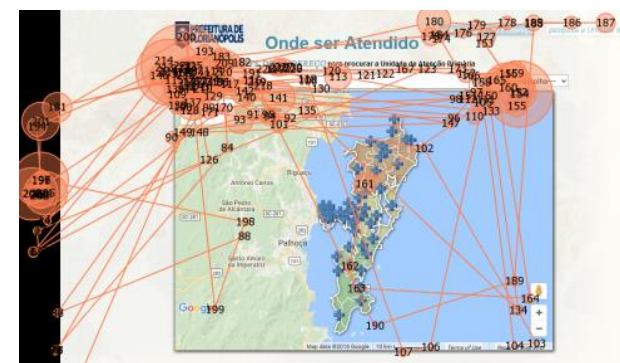

Figura 10: Mapa de Fixações (Gazeplot) da Tarefa 2 para o Participante 1 (P1).

Fonte: Print Screen do programa de análise dos dados do eye tracking (BeeGaze).

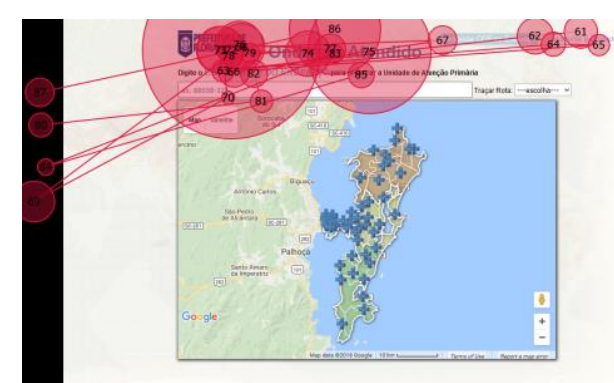

Figura 11: Mapa de Fixações (Gazeplot) da Tarefa 2 para o Participante $2(\mathrm{P} 2)$.

Fonte: Print Screen do programa de análise dos dados do eye tracking (BeeGaze).

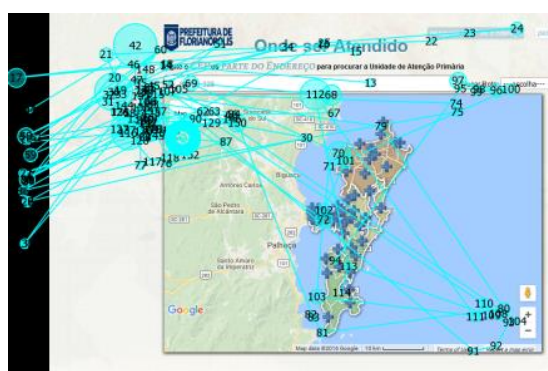

Figura 12: Mapa de Fixações (Gazeplot) da Tarefa 2 para o Participante 3 (P3).

Fonte: Print Screen do programa de análise dos dados do eye tracking (BeeGaze).

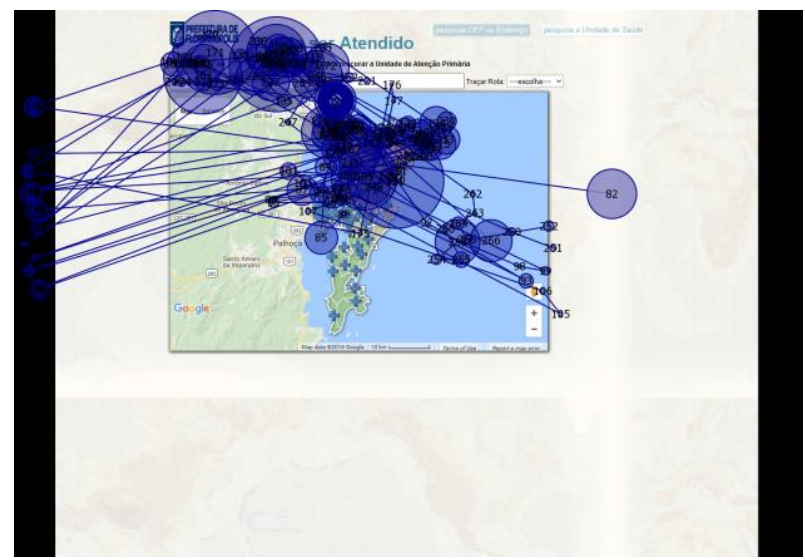

Figura 13: Mapa de Fixações (Gazeplot) da Tarefa 2 para o Participante 4 (P4).

Fonte: Print Screen do programa de análise dos dados do eye tracking (BeeGaze).



Figura 14: Mapa de Fixações (Gazeplot) da Tarefa 2 para o Participante 5 (P5).

Fonte: Print Screen do programa de análise dos dados do eye tracking (BeeGaze).

Após a coleta de dados com o eye tracker, cada participante preencheu o questionário SUS e o 


\section{$16^{\circ}$ \\ ERGODESIGN USIHC CINAHPA}

PrEmo. Os resultados de todos os participantes para estes questionários estão agrupados na Tabela 1 e no Quadro 1.

\begin{tabular}{|c|c|c|c|c|c|c|c|}
\hline \multirow[b]{2}{*}{ Questão } & \multicolumn{5}{|c|}{ Usuário } & \multirow[b]{2}{*}{ Média } & \multirow[b]{2}{*}{$\begin{array}{l}\text { Desv. } \\
\text { Pad. }\end{array}$} \\
\hline & P1 & P2 & P3 & P4 & P5 & & \\
\hline \begin{tabular}{|l|l|}
$\mathbf{1}$ & $\begin{array}{l}\text { Desejo de usar } \\
\text { com frequência }\end{array}$ \\
\end{tabular} & 2 & 4 & 5 & 5 & 2 & 3.60 & 1.52 \\
\hline 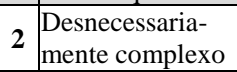 & 3 & 3 & 1 & 2 & 2 & 2.20 & 0.84 \\
\hline \begin{tabular}{l|l}
3 & Fácil de Usar \\
\end{tabular} & 3 & 4 & 5 & 4 & 4 & 4.00 & 0.71 \\
\hline $4 \begin{array}{l}\text { Necessário } \\
\text { suporte técnico } \\
\text { para uso }\end{array}$ & 1 & 1 & 1 & 4 & 2 & 1.80 & 1.30 \\
\hline 5 \begin{tabular}{l|l}
$\begin{array}{l}\text { Funções bem } \\
\text { integradas }\end{array}$ \\
\end{tabular} & 3 & 3 & 4 & 5 & 3 & 3.60 & 0.89 \\
\hline \begin{tabular}{l|l}
6 & $\begin{array}{l}\text { Muito } \\
\text { inconsistente }\end{array}$ \\
\end{tabular} & 4 & 2 & 1 & 2 & 4 & 2.60 & 1.34 \\
\hline $7 \begin{array}{l}\text { As pessoas terão } \\
\text { facilidade de } \\
\text { aprender }\end{array}$ & 4 & 4 & 5 & 4 & 2 & 3.80 & 1.10 \\
\hline \begin{tabular}{l|l}
8 & $\begin{array}{l}\text { Muito estranho } \\
\text { de utilizar }\end{array}$ \\
\end{tabular} & 4 & 3 & 1 & 3 & 3 & 2.80 & 1.10 \\
\hline $9 \begin{array}{l}\text { Sentiu-se } \\
\text { confiante ao usar }\end{array}$ & 3 & 4 & 5 & 3 & 2 & 3.40 & 1.14 \\
\hline $10 \mid \begin{array}{l}\text { Precisa aprender } \\
\text { muitas coisas } \\
\text { antes de usar }\end{array}$ & 1 & 1 & 1 & 2 & 3 & 1.60 & 0.89 \\
\hline Pontos & 55.0 & 72.5 & 97.5 & 70.0 & 47.5 & & \\
\hline Classificação & Reg & Bom & Aldet & gou & 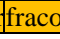 & & \\
\hline
\end{tabular}

Tabela 1: Pontuação SUS dos participantes.

Fonte: Tullis \& Albert (2013).

\begin{tabular}{|l|l|l|l|}
\hline Participante & Tarefa 1 & Tarefa 2 & Emoção \\
\hline Participante 1 & Indignação & Insatisfação & Negativa \\
\hline Participante 2 & $\begin{array}{l}\text { Surpresa } \\
\text { Agradável }\end{array}$ & Fascínio & Positiva \\
\hline Participante 3 & Orgulho & Orgulho & Positiva \\
\hline Participante 4 & Insatisfeito & Insatisfeito & Negativa \\
\hline Participante 5 & Desejo & Insatisfeito & Positiva/Negativa \\
\hline
\end{tabular}

Quadro 1: Resultados prEmo.

Fonte: Os autores.

Para cada candidato, também foram analisadas as dispersões das fixações, ou seja, as fixações que se encontram fora das áreas de interesse da tela. Esses resultados estão na Tabela 2. $16^{\circ}$ Ergodesign - Congresso Internacional de Ergonomia e Usabilidade de Interfaces Humano Tecnológica: Produto, Informações Ambientes Construídos e Transporte

$16^{\circ}$ USIHC - Congresso Internacional de Ergonomia e Usabilidade de Interfaces Humano Computador

CINAHPA | 2017 - Congresso Internacional de Ambientes Hipermídia para Aprendizagem.

\begin{tabular}{|c|c|c|c|c|}
\hline Participante & $\begin{array}{c}\text { Fixações } \\
\text { tarefa 1 }\end{array}$ & $\begin{array}{c}\text { Dispersões } \\
\text { tarefa 1 }\end{array}$ & $\begin{array}{c}\text { Fixações } \\
\text { tarefa 2 }\end{array}$ & $\begin{array}{c}\text { Dispersões } \\
\text { tarefa 2 }\end{array}$ \\
\hline P1 & 26 & 6 & 96 & 63 \\
\hline P2 & 19 & 3 & 22 & 4 \\
\hline P3 & 5 & 7 & 110 & 30 \\
\hline P4 & 24 & 49 & 157 & 38 \\
\hline P5 & 1 & 25 & 82 & 37 \\
\hline
\end{tabular}

Tabela 2: Número de fixações e dispersões dos participantes nas duas tarefas.

Fonte: Os autores.

Com os dados das Tabelas 1 e 2 e do Quadro 1, foi criado o gráfico da Figura 15, que demonstra o número de fixações em relação à pontuação do SUS, juntamente com a classificação do PrEmo, para cada participante.

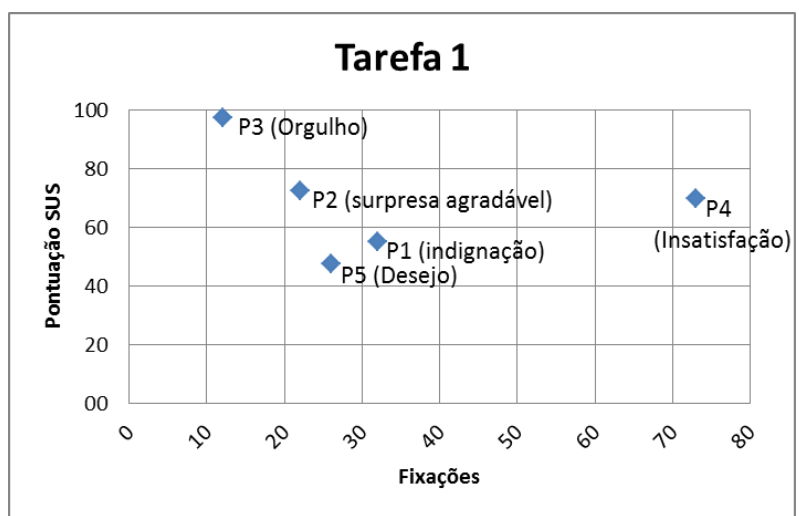

Figura 15: Comparação entre o número de fixações dos participantes na Tarefa 1 com a pontuação SUS e classificação do PrEmo. Fonte: Os autores.

Pela análise do Gráfico da Figura 15, pode-se perceber que existe uma tendência de quanto menor o número de fixações, maior o nível de satisfação obtido no teste SUS. Esse resultado está de acordo com pesquisas de outros autores, que demonstraram que o número de fixações mais alto pode indicar uma alta carga cognitiva (IQBAL et al., 2005; SCHULTHEIS \& JAMESON, 2004). A carga cognitiva elevada pode estar associada à 


\section{$16^{\circ}$ \\ ERGODESIGN USIHC CINAHPA}

dificuldade de completar tarefas e, consequentemente, à insatisfação na interação com a interface (CHENG \& LIU, 2012; NIELSEN \& LEVY; 1994).

Para auxiliar a análise do gráfico, foi criada uma classificação do número de fixações em alta, média e baixa, com base na observação das tarefas de todos os candidatos (Quadro 2).

\begin{tabular}{|llll|}
\hline Tarefa 1 & Baixo & Médio & Alto \\
& Menor que 10 & Entre 10 e 20 & Maior que 20 \\
Tarefa 2 & Baixo & Médio & Alto \\
& Menor que 65 & Entre 65 e 125 & Maior que 125 \\
\hline
\end{tabular}

Quadro 2: Número de fixações dos níveis de fixação das duas tarefas.

Fonte: Os autores.

Na Tarefa 1, os participantes P4 e P5 foram os que tiveram maior dispersão das fixações (Tabela 2), o que pode indicar dificuldade de encontrar o que se busca na tela. Esses dois participantes pontuaram valores relativamente baixos no teste SUS (regular e fraco, conforme Tabela 1). O participante P1 também obteve pontuação classificada como regular no teste SUS, porém, as fixações não se mostraram tão dispersas (Figura 10), quanto os participantes P4 e P5 (Figuras 8 e 9), tornando a análise deste participante inconclusiva.

De forma análoga, os participantes P2 e P3 tiveram uma dispersão de fixações menor (entre 3 e 7 fixações fora das áreas de interesse, conforme a Tabela 2, e pontuações no SUS mais altas (classificadas como bom e excelente, respectivamente), indicando novamente que a dispersão das fixações do olhar pode estar inversamente associada com a satisfação do usuário.

Para a análise da Tarefa 2, foi criado um gráfico com os dados das Tabelas 1 e 2 e do Quadro 1 (Figura 16), comparando o número de fixações dos participantes com a pontuação do SUS e emoções do PrEmo. $16^{\circ}$ Ergodesign - Congresso Internacional de Ergonomia e Usabilidade de Interfaces Humano Tecnológica: Produto, Informações Ambientes Construídos e Transporte

$16^{\circ}$ USIHC - Congresso Internacional de Ergonomia e Usabilidade de Interfaces Humano Computador

CINAHPA | 2017 - Congresso Internacional de Ambientes Hipermídia para Aprendizagem.

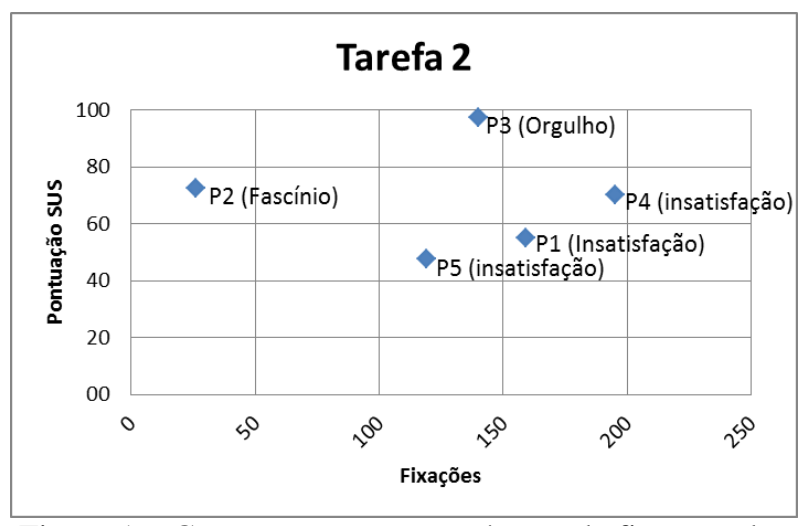

Figura 16: Comparação entre o número de fixações dos participantes na tarefa 2 com a pontuação SUS e emoções do PrEmo.

Fonte: Os autores.

Na tarefa 2, conforme demonstrado no gráfico da Figura 16, os participantes P1 e P4 foram os candidatos que obtiveram maior número de fixações e suas pontuações no SUS foram classificadas como regulares. Os resultados do participante P2 mostram pouco número de fixações (em relação aos demais candidatos) e pontuação no SUS classificada como boa. O participante P5 obteve um número de fixações menor do que os participantes P1 e P4, sendo que sua resposta no questionário SUS foi classificada como ruim. $\mathrm{O}$ Participante P3 obteve um número de fixações alto, embora sua resposta no questionário SUS tenha sido positiva (boa), fugindo do padrão dos candidatos anteriores.

Quanto à dispersão das fixações nesta tarefa, os participantes P1 e P4 e P5 foram os que obtiveram maior número de fixações fora das áreas de interesse (63, 38 e 37, respectivamente). Esses mesmos participantes classificaram a interface como regular ou ruim no teste SUS. Para o participante $\mathrm{P} 2$, que classificou a interface como boa no teste SUS, o número de dispersões ficou em apenas 4 fixações. Já o participante P3 obteve 30 fixações fora das áreas de interesse, embora tenha classificado a interface como boa no teste SUS.

Analisando a correspondência entre os testes SUS e Premo, foi constatado que no teste PrEmo, os participantes P1 e P4 demonstraram emoções negativas para as duas tarefas dadas (insatisfação), conforme o Quadro 1. Os resultados estão 


\section{$16^{\circ}$ \\ ERGODESIGN USIHC CINAHPA}

parcialmente de acordo com o resultado do SUS, em que os participantes classificaram a interface como regular. Como já visto anteriormente, esses participantes foram os que obtiveram também o maior número de fixações e de dispersões de fixações na tarefa 2 , sendo que na tarefa 1 , o participante $\mathrm{P} 4$ também obteve um número alto de fixações, mas baixo de dispersão. Por outro lado, o participante $\mathrm{P} 2$ obteve um baixo número de fixações, e emoções positivas nas duas tarefas, conforme o teste PrEmo (Surpresa Agradável e Fascínio). Esses resultados indicam que o número de fixações e a dispersão de fixações também podem estar relacionadas à satisfação do usuário, corroborando os resultados obtidos com o PrEmo. Apenas o participante $\mathrm{P} 3$ obteve resultados que demonstraram o contrário (alta fixação, alta dispersão e emoção positiva no PrEmo (orgulho para as duas tarefas).

\section{CONCLUSÃO}

Os resultados obtidos com o uso da técnica eye tracking, em sua maioria, demonstraram, de forma geral, que quanto maior o número de fixações e quanto maior o número de dispersão das fixações, mais negativos eram os resultados obtidos tanto no questionário SUS como no Premo. Os dados levantados nesta pesquisa sugerem que existe uma relação inversa entre o número de fixações e o número de dispersão das fixações, em uma interface web, e a satisfação. Esses resultados são importantes, pois pode possibilitar o uso do eye tracking para a obtenção de dados quantitativos relativos à medida da satisfação, evitando, dessa maneira, os problemas dos dados subjetivos, como constrangimentos ou tendenciosidade ao responder questionários, falhas de interpretação, tanto de questionários como de análises de dados, e erros de percepção tanto por parte dos usuários como por parte do pesquisador (BERTRAND \& MULLAINATHAN, 2001).

É importante ressaltar que esta pesquisa possui algumas limitações por ser um estudo preliminar. O tamanho da amostra $(n=5)$ foi pequeno, o que não favorece análises estatísticas aprofundadas, necessárias para uma conclusão mais confiável. Sugere-se que o tamanho da amostra seja $16^{\circ}$ Ergodesign - Congresso Internacional de Ergonomia e Usabilidade de Interfaces Humano Tecnológica: Produto, Informações Ambientes Construídos e Transporte

$16^{\circ}$ USIHC - Congresso Internacional de Ergonomia e Usabilidade de Interfaces Humano Computador

CINAHPA | 2017 - Congresso Internacional de Ambientes Hipermídia para Aprendizagem. aumentado em estudos futuros. Além disso, houve problemas de calibração do eye tracker, o que resultou em exclusão de alguns participantes antes da análise dos resultados do teste.

Outra limitação diz respeito aos dados analisados. Nesta pesquisa foi possível analisar apenas os dados referentes às fixações e suas dispersões. Em estudos posteriores, pretende-se analisar outros dados, como o número de piscadas, e os movimentos sacádicos.

Apesar das limitações, foi observado, neste teste, que existe a possibilidade de medir a satisfação do usuário em interfaces gráficas com o uso de eye tracking por meio da análise das fixações do olhar e suas dispersões, como complemento de questionários de satisfação. Foi sugerido que as fixações e as dispersões são inversamente proporcionais à satisfação do usuário, mas existe a necessidade de mais estudos na área para uma conclusão mais concreta.

\section{AGRADECIMENTOS}

Agradecemos ao CNPq, pelo financiamento dos bolsistas envolvidos na pesquisa, e ao NGD (Núcleo de Gestão de Design) e LDU (Laboratório de Design e Usabilidade) que forneceu o uso do equipamento eye tracking para esta pesquisa.

\section{BIBLIOGRAFIA}

BERGSTRAM, J. R.; SCHALL, A. J. Eye Tracking in User Experience Design. Elsevier, 2014.

BERTRAND, M.; MULLAINATHAN, S. Do people mean what they say? Implications for subjective survey data. The American Economic Review, v. 91, n. 2, p. 67-72, 2001.

BROOKE, J. SUS: A retrospective. Journal of usability studies. Vol. 8, pp. 29-40, fev. 2013.

IIDA, I.; BUARQUE, L. Ergonomia: Projeto e Produção. São Paulo: Blucher, 2016.

CAICEDO, G.D; DESMET, P.M.A. Designing the
Realização:

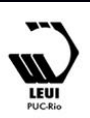


new PrEmo. An empirical research on how to improve the emotion measuring tool. Delft University of Technology, 2009.

CHENG, S.; LIU, Y. Eye-tracking based adaptive user interface: implicit human-computer interaction for preference indication. Journal on Multimodal User Interfaces, v. 5, n. 1-2, p. 77 84, 2012.

GRANKA, L.; FEUSNER, M.; LORIGO, L. Eye monitoring in online search. In R. I. Hammoud, editor, Passive Eye Monitoring, Signals and Communication Technology, pages 347-372. Springer, 2008.

IQBAL, S., ADAMZYCK, P., ZHENG, X.; BAILEY, P. Towards an index of opportunity: Understanding changes in mental workload during task execution. Proceedings of CHI 2005:

Human Factors in Computing Systems, 311320, 2005.

ISO 9241-11: Ergonomic requirements for office work with visual display terminals (VDTs). Part 11 — Guidelines for specifying and measuring usability. Gènève: International Organisation for Standardisation, 1998.

BERGSTROM, J. R.; SCHALL, A. (Ed.). Eye tracking in user experience design. Elsevier, 2014.

MCINTIRE, L.; K, MCKINLEY; GOODYEAR, C.; MCINTIRE, J. Detection of vigilance performance using eye blinks. Applied ergonomics, v. 45, n. 2, p. 354-362, 2014.

NIELSEN, J.;LEVY, J. Measuring usability: preference vs. performance. Communications of the ACM, 37(4), 66-75, 1994.

POOLE, A., BALL, L.J. Eye tracking in humancomputer interaction and usability research: current status and future prospects. In: Ghaoui, C. (Ed.), Encyclopedia of Human Computer Interaction. Idea Group, Hershey, PA, pp. 211219, 2005.

PREFEITURA DE FLORIANÓPOLIS. Disponível $16^{\circ}$ Ergodesign - Congresso Internacional de Ergonomia e Usabilidade de Interfaces Humano Tecnológica: Produto, Informações Ambientes Construídos e Transporte

$16^{\circ}$ USIHC - Congresso Internacional de Ergonomia e Usabilidade de Interfaces Humano Computador

CINAHPA | 2017 - Congresso Internacional de Ambientes Hipermídia para Aprendizagem.

em: http://www.pmf.sc.gov.br/saude. Acesso em out. 2016.

SCHULTHEIS, H.; JAMESON, A. Assessing cognitive load in adaptive hypermedia systems: Physiological and behavioural methods. In W. NEIJDL \& P. DE BRA (Eds.), Adaptive hypermedia and adaptive web-based systems (pp. 18-24). Eindhoven, the Netherlands: Springer Verlag, 2004.

SMI SensoMotoric Instruments. Disponível em: www.smivision.com. Acesso em: 25 nov. 2016.

TSAI, Y., VIIRRE, E., STRYCHACZ, C., CHASE, B., JUNG, T. Task performance and eye activity: predicting behavior relating to cognitive workload. Aviat. Space Environ. Med. 78 (5.2), B176eB185, 2007.

TULLIS, T., \& ALBERT, B. Measuring the user experience: collecting, analysing, and presenting usability matrics. London: MK Elsevier, 2013.
Realização:

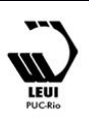

